Archives de sciences sociales des religions

$168 \mid 2014$

Bulletin Bibliographique

\title{
Arnaud Esquerre, Les os, les cendres et l'État
}

Paris, Fayard, 2011, 328 p.

Gaspard Salatko

\section{(2) OpenEdition}

Journals

Édition électronique

URL : https://journals.openedition.org/assr/26399

DOI : $10.4000 /$ assr.26399

ISSN : $1777-5825$

Éditeur

Éditions de l'EHESS

Édition imprimée

Date de publication : 31 décembre 2014

Pagination : 181

ISBN : 978-2-7132-2467-6

ISSN : 0335-5985

Référence électronique

Gaspard Salatko, «Arnaud Esquerre, Les os, les cendres et l'État », Archives de sciences sociales des religions [En ligne], 168 | 2014, mis en ligne le 15 avril 2015, consulté le 21 septembre 2021. URL : http://journals.openedition.org/assr/26399; DOI : https://doi.org/10.4000/assr.26399

Ce document a été généré automatiquement le 21 septembre 2021.

(c) Archives de sciences sociales des religions 


\section{Arnaud Esquerre, Les os, les cendres et l'État}

Paris, Fayard, 2011, 328 p.

Gaspard Salatko

\section{RÉFÉRENCE}

Arnaud Esquerre, Les os, les cendres et l'État, Paris, Fayard, 2011, 328 p. 
1 L'ouvrage d'Arnaud Esquerre a pour projet de mettre en évidence les différentes modalités et/ou acceptions du rapport que les vivants entretiennent avec les « restes humains ». Il s'agit là d'une catégorie extensive dont l'emploi réfère aux éléments d'origine organique (os, organes, momies, cendres, reliques, cadavres, spécimens médicaux...) résultant de la transformation religieuse, politique, médicale ou même artistique d'êtres humains défunts. À l'exception de quelques excursus statistiques visant à mettre en évidence l'évolution de la pratique de la crémation en Europe, l'enquête juxtapose quatre terrains, en apparence disjoints, que l'auteur relie en analysant la façon dont l'exercice du droit français procède, depuis le XIX ${ }^{\mathrm{e}}$ siècle, à un travail constant de définition et de qualification dont l'enjeu consiste à

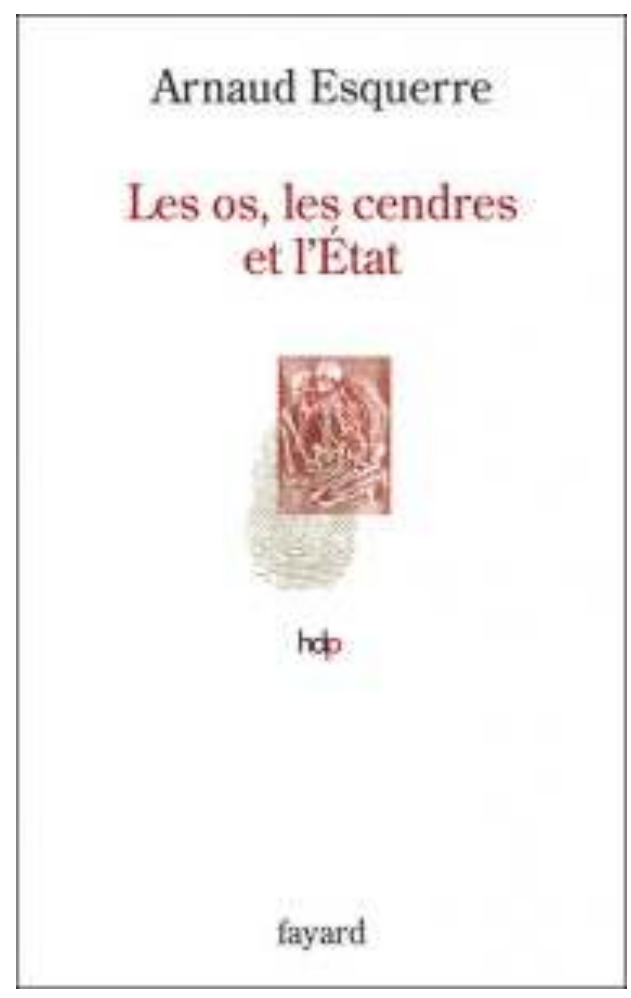
établir des équivalences entre ces restes et les personnes physiques ou morales d'où ces restes sont issus et auxquels ils réfèrent.

La première partie du travail, qui situe la crémation et sa diffusion sous perspective historique, retrace les controverses dont cette pratique a fait l'objet depuis la Révolution française jusqu'au début $\mathrm{du} \mathrm{xxI}^{\mathrm{e}}$ siècle. Dès la Révolution, la disparition du monopole jusqu'alors exercé par l'Église concernant la gestion des morts et de leur corps conduit des réformateurs laïcs à envisager, selon une perspective culturellement renouvelée, le devenir des corps et les soins qu'il convient de leur porter. Entre 1794 et 1804, les débats sur la crémation introduisent la question du droit des individus à disposer de leur corps, posant de fait la question de l'inscription des cadavres dans l'espace public. Si ces débats n'aboutissent ni à une autorisation ni à une interdiction explicite, ils annoncent les arguments qui, à la fin du XIX siècle, seront repris et amplifiés sous l'action de la Société de crémation qui, mobilisant dans son sillage un mince collectif, " composé principalement de bourgeois et de petits bourgeois laïcs » (p. 82), constitué autour d'arguments éthiques et hygiénistes obtient, contre l'avis de l'institution ecclésiale et de ses représentants, l'autorisation explicite de la crémation. Pour autant, la question de l'usage des cendres n'est que provisoirement stabilisée. Près de cent ans plus tard, en 1971, à la demande de la Fédération nationale des sociétés françaises de crémation, le gouvernement français introduit, par décret, une réforme visant à libéraliser l'usage des cendres dont disposeront désormais les familles qui pourront les conserver, les partager ou les disséminer dans la nature. Cette gestion privée des cendres confère aux morts une mobilité nouvelle sur laquelle les législateurs reviennent au début $\mathrm{du} \mathrm{xxI}^{\mathrm{e}}$ siècle en promulguant la loi du 19 décembre 2008 qui introduit, au nom du respect d'un principe moral de deuil, l'obligation d'assigner à chaque défunt une place fixe dans l'espace public. Dans ce contexte, l'auteur suit pas à pas le travail de qualification mené par les parlementaires qui, soucieux d'encadrer le 
devenir des cendres, établissent leur équivalence avec les cadavres, mettant de fait un terme à la circulation des morts.

À partir de ce travail de contextualisation historique et sociologique, l'auteur met au jour, dans une seconde partie, la labilité des formes de critique et de contrôle juridique qui accompagnent et contraignent la présentation publique des restes humains. L'analyse prend appui sur l'examen des réactions suscitées par la monstration de cadavres "plastinés » et mis en scène dans le cadre de l'exposition Our Body. À corps ouvert, interdite en France sur décision de justice après avoir été présentée en 2009 à Marseille, Lyon, puis Paris. L'auteur, qui mobilise ici les ressources méthodologiques de l'ethnographie, examine les arguments qui ont présidé à la fermeture de cette exposition au regard des pratiques qui encadrent actuellement la présentation ecclésiale et muséale des restes humains. Tandis que les usages liés à la vénération de " la sainte couronne d'épines du Christ », périodiquement présentée dans la cathédrale Notre-Dame de Paris, et le corps reliquaire de Vincent de Paul, exposé dans la chapelle parisienne des Lazaristes, procèdent d'un dispositif visuel et tactile d'accès aux personnes saintes par l'entremise de leur(s) relique(s), l'ethnographie d'Arnaud Esquerre montre que les réactions que manifestent les visiteurs des musées Dupuytrene, Fragonard et au Louvre, face aux pièces anatomiques, aux écorchés et aux momies qui y sont exposés, relèvent d'un système manifeste d'appréciation esthétique. Par ce travail, l'auteur distingue les processus de mémoire et d'oubli qui sous-tendent la fabrication des reliques, celle des spécimens médicaux, mais aussi celle des formes artistiques et des "archives» ethnographiques qui intègrent parfois des restes humains et dont l'auteur envisage, en se basant notamment sur la controverse liée aux prélèvements réalisés sur la dépouille de Saartjie Baartman, la restitution aux collectifs ou aux communautés qui en revendiquent l'appartenance. L'engagement de l'État quant au traitement des restes humains se trouve au cœur de la troisième partie de l'ouvrage où l'auteur envisage, principalement à partir de l'affaire de la profanation du cimetière juif de Carpentras, l'introduction dans les années 1990 de la catégorie juridique de "profanation» qui étend aux objets constitutifs des sépultures et aux monuments aux morts les qualités attribuées aux restes humains défunts.

4 Enfin, la question du traitement dévolu aux défunts suspects, qui conduit le lecteur jusque dans le laboratoire du médecin légiste, met un point d'orgue à la description du processus, toujours renégocié, par lequel l'État entend disposer, sur un territoire donné, des morts «en leur totalité ». En pointant la façon dont la pratique du droit instaure des équivalences entre les êtres (vivants et défunts) et les choses (restes humains, sépultures et monuments aux morts) dont les États disposent, le travail d'Arnaud Esquerre s'inscrit sous une perspective résolument pragmatique, nourrie aux sources de l'histoire, de la sociologie et de l'anthropologie. De ce point de vue, la question de la dissémination des morts par le biais des indices de leur existence passée constitue une modalité largement inexplorée du problème de l'agentivité - pour peu que l'on s'en tienne à désigner sous ce néologisme la propriété qu'ont les choses à se substituer en certaines circonstances à des êtres humains ou non humains. En particulier, les controverses engagées au sujet de la pratique de la crémation ou des profanations de sépultures, les formes d'appréciation visuelles et olfactives que supportent les reliques (et qui permettent à l'auteur de mobiliser des comparaisons fructueuses avec les travaux de David Freedberg qui analysait naguère la capacité des images à susciter chez leur(s) contemplateur(s) des réactions de caractère spectaculaire), jusqu'au rapport olfactif que le médecin légiste entretient avec les 
cadavres qui lui sont confiés, suggèrent que les restes humains constituent, en situation, des embrayeurs privilégiés d'action et de perception. Outre la richesse des données mises en perspective, cette enquête constitue sous ces différents aspects une contribution significative au champ de l'anthropologie de la présence que l'invention de nouvelles pratiques et que l'instauration de nouveaux corpus d'énoncés juridiques ne laisse pas de renouveler. 